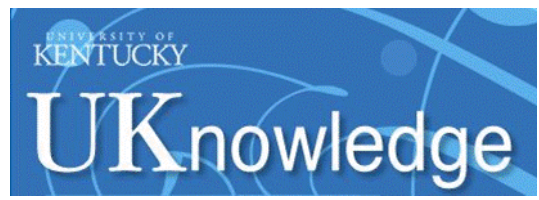

University of Kentucky

UKnowledge

Spinal Cord and Brain Injury Research Center Faculty Publications

$10-1-2017$

\title{
Acute Treatment with Doxorubicin Affects Glutamate Neurotransmission in the Mouse Frontal Cortex and Hippocampus
}

\author{
Theresa Currier Thomas \\ University of Kentucky \\ Joshua A. Beitchman \\ University of Arizona \\ Francois Pomerleau \\ University of Kentucky, francois.pomerleau@uky.edu \\ Teresa Noel \\ University of Kentucky, tperron@email.uky.edu \\ Paiboon Jungsuwadee \\ University of Kentucky, paiboon.jungsuwadee@uky.edu \\ Follow this and additional works at: https://uknowledge.uky.edu/scobirc_facpub \\ 2 next page for additional authors \\ Part of the Neurology Commons, and the Neuroscience and Neurobiology Commons \\ Right click to open a feedback form in a new tab to let us know how this document benefits you.
}

\section{Repository Citation}

Thomas, Theresa Currier; Beitchman, Joshua A.; Pomerleau, Francois; Noel, Teresa; Jungsuwadee, Paiboon; Butterfield, D. Allan; St. Clair, Daret K.; Vore, Mary; and Gerhardt, Greg A., "Acute Treatment with Doxorubicin Affects Glutamate Neurotransmission in the Mouse Frontal Cortex and Hippocampus" (2017). Spinal Cord and Brain Injury Research Center Faculty Publications. 26.

https://uknowledge.uky.edu/scobirc_facpub/26

This Article is brought to you for free and open access by the Spinal Cord and Brain Injury Research at UKnowledge. It has been accepted for inclusion in Spinal Cord and Brain Injury Research Center Faculty Publications by an authorized administrator of UKnowledge. For more information, please contact UKnowledge@lsv.uky.edu. 


\title{
Acute Treatment with Doxorubicin Affects Glutamate Neurotransmission in the Mouse Frontal Cortex and Hippocampus
}

\author{
Digital Object Identifier (DOI) \\ https://doi.org/10.1016/j.brainres.2017.07.003 \\ Notes/Citation Information \\ Published in Brain Research, v. 1672, p. 10-17. \\ (C) 2017 Elsevier B.V. All rights reserved.
}

This manuscript version is made available under the CC-BY-NC-ND 4.0 license https://creativecommons.org/licenses/by-nc-nd/4.0/.

The document available for download is the author's post-peer-review final draft of the article.

\section{Authors}

Theresa Currier Thomas, Joshua A. Beitchman, Francois Pomerleau, Teresa Noel, Paiboon Jungsuwadee, D. Allan Butterfield, Daret K. St. Clair, Mary Vore, and Greg A. Gerhardt 
Published in final edited form as:

Brain Res. 2017 October 01; 1672: 10-17. doi:10.1016/j.brainres.2017.07.003.

\title{
Acute Treatment with Doxorubicin Affects Glutamate Neurotransmission in the Mouse Frontal Cortex and Hippocampus
}

\author{
Theresa Currier Thomas ${ }^{a, h, i, j}$, Joshua A. Beitchman ${ }^{\mathrm{i}, \mathrm{j}, \mathrm{k}}$, Francois Pomerleau ${ }^{\mathrm{b}, \mathrm{c}, \mathrm{d}}$, Teresa \\ Noel $^{e}$, Paiboon Jungsuwadee ${ }^{e, l}$, D. Allan Butterfield ${ }^{\dagger}$, Daret K. Clair St. ${ }^{e}$, Mary Vore ${ }^{e}$, and \\ Greg A. Gerhardta,b,c,d \\ aSpinal Cord \& Brain Injury Research Center, University of Kentucky College of Medicine, \\ Lexington, KY, USA 40536 \\ bDepartments of Neuroscience, Neurology, Neurosurgery, Psychiatry and Electrical Engineering, \\ University of Kentucky College of Medicine, Lexington, KY, USA 40536 \\ 'Center for Microelectrode Technology, University of Kentucky College of Medicine, Lexington, KY, \\ USA 40536 \\ ${ }^{\mathrm{d} B r a i n}$ Research Center, University of Kentucky College of Medicine, Lexington, KY, USA 40536 \\ eDepartment of Toxicology and Cancer Biology, University of Kentucky College of Medicine, \\ Lexington, KY, USA 40536 \\ fDepartment of Chemistry, Redox Chemistry and Biology Core, Markey Cancer, and Sanders- \\ Brown Center on Aging, University of Kentucky, Lexington, KY, USA 40506 \\ hBarrow Neurological Institute at Phoenix Children's Hospital, Phoenix, AZ USA 85016 \\ 'Department of Child Health, University of Arizona College of Medicine, Phoenix, AZ USA 85004 \\ jPhoenix VA Health Care System, Phoenix, AZ USA 85012 \\ kMidwestern University, Glendale, AZ USA 85308 \\ ISchool of Pharmacy \& Health Sciences, Fairleigh Dickinson University, Florham Park, NJ, USA \\ 07932
}

\begin{abstract}
Doxorubicin (DOX) is a potent chemotherapeutic agent known to cause acute and long-term cognitive impairments in cancer patients. Cognitive function is presumed to be primarily mediated
\end{abstract}

\footnotetext{
Address correspondence to (Present address): Theresa Currier Thomas, PhD, Assistant Professor, Department of Child Health, Translational Neurotrauma Research Program, University of Arizona, College of Medicine-Phoenix, Barrow Neurological Institute at Phoenix Children's Hospital 425 N. 5th St.; ABC-1 Bldg., Third Floor Phoenix, Arizona 85004, theresathomas@email.arizona.edu; tdcurr00@ gmail.com, Tel: (859) 433-8954, Fax: (602) 827-2257.

Conflicts of Interest: Greg A. Gerhardt is the sole proprietor of Quanteon, LLC

Publisher's Disclaimer: This is a PDF file of an unedited manuscript that has been accepted for publication. As a service to our customers we are providing this early version of the manuscript. The manuscript will undergo copyediting, typesetting, and review of the resulting proof before it is published in its final citable form. Please note that during the production process errors may be discovered which could affect the content, and all legal disclaimers that apply to the journal pertain.
} 
by neuronal circuitry in the frontal cortex (FC) and hippocampus, where glutamate is the primary excitatory neurotransmitter. Mice treated with DOX $(25 \mathrm{mg} / \mathrm{kg}$ i.p.) were subjected to in vivo recordings under urethane anesthesia at 24h post-DOX injection or 5 consecutive days of cognitive testing (Morris Water Maze; MWM). Using novel glutamate-selective microelectrode arrays, amperometric recordings measured parameters of extracellular glutamate clearance and potassium-evoked release of glutamate within the medial FC and dentate gyrus (DG) of the hippocampus. By $24 \mathrm{~h}$ post-DOX injection, glutamate uptake was $45 \%$ slower in the FC in comparison to saline-treated mice. In the DG, glutamate took $48 \%$ longer to clear than salinetreated mice. Glutamate overflow in the FC was similar between treatment groups, however, it was significantly increased in the DG of DOX treated mice. MWM data indicated that a single dose of DOX impaired swim speed without impacting total length traveled. These data indicate that systemic DOX treatment changes glutamate neurotransmission in key nuclei associated with cognitive function within $24 \mathrm{~h}$, without a lasting impact on spatial learning and memory. Understanding the functional effects of DOX on glutamate neurotransmission may help us understand and prevent some of the debilitating side effects of chemotherapeutic treatment in cancer survivors.

\section{Keywords}

Doxorubicin; Chemobrain; Prefrontal Cortex; Dentate Gyrus; Amperometry; Glutamate Clearance

\subsection{Introduction}

Doxorubicin (DOX), trade name Adriamycin, is a potent chemotherapeutic agent, often used synergistically with other drug regimens for the treatment of cancer. Following DOX chemotherapy, breast cancer survivors report persisting cognitive dysfunction (Aluise et al., 2010; Raffa and Tallarida, 2010; Wefel et al., 2004). Chemotherapy-induced cognitive impairment (CICI) is a term often used to indicate significant impairments in concentration, verbal learning, nonverbal learning, memory function, attention and fine motor dexterity (Ahles et al., 2002; Tangpong et al., 2006; Wefel et al., 2004).

At the present time, little is known about the direct effects of DOX treatment on cognitive circuitry in vivo. DOX and it's major metabolites do not cross the blood brain barrier, yet cognitive impairment is often reported. Therefore, a gap in knowledge exists as to the mechanisms by which DOX treatment can influence cognition. Cognitive processes are mediated by glutamatergic communication between the frontal cortex (FC) and dentate gyrus (DG) of the hippocampus. We hypothesize that a single dose of DOX can produce changes in glutamate neurotransmission in brain areas where the primary excitatory neurotransmitter is glutamate (Danbolt, 2001). DOX-induced changes in glutamate neurotransmission would confirm that a single dose of DOX is capable of altering in vivo glutamate signaling in this circuitry and identify a mechanism as to how DOX treatment could consequently contribute to CICI acutely and after a chronic dosing regimen.

Recent technological advancements have provided enzyme-based glutamate-selective microelectrode arrays (MEAs) using amperometric recordings for the sub-second 
measurements of glutamate neurotransmission in animal models (Burmeister et al., 2002). These techniques have been previously used to investigate phasic glutamate signaling in discrete brain area of rats and mice (Hinzman et al., 2010; Stephens et al., 2011; Thomas et al., 2009; Thomas et al., 2012). In these experiments, mice were treated with $25 \mathrm{mg} / \mathrm{kg}$ of DOX and subjected to in vivo recordings in 3 sub-regions of the mouse FC and the DG $24 \mathrm{~h}$ post-treatment to investigate potential acute changes in glutamate regulation (see figure 1A). In an alternate cohort of mice, the Morris Water Maze (MWM) test was used as an initial indicator of their cognitive function.

\subsection{Results}

\subsection{Glutamate Clearance Parameters in the FC and DG}

Local application of exogenous glutamate was used to evaluate the effect of DOX treatment on glutamate clearance from the extracellular space of the mouse brain. Two different parameters were calculated from the resulting peak: (1) the uptake rate constant $\left(\mathrm{k}_{-1}\right)$, which is the linear fit of the first order decay of the glutamate signal $\left(\mathrm{sec}^{-1}\right)$ and (2) $\mathrm{T}_{80}$ clearance time (sec), which is the time it takes for the signal to decay $80 \%$ from the maximum amplitude (see figure 1).

Recordings demonstrated a significant decline of the uptake rate constant measured at various depths in the $\mathrm{FC}(\mathrm{F}(1,9)=7.45 ; \mathrm{p}=0.02$; Figure $2 \mathrm{~A})$, where the most profoundly impacted depth corresponded to the infralimbic cortex $(-2.5 \mathrm{~mm} ; \mathrm{p}<0.01)$. The uptake rate constant in the averaged depths of the FC was $0.44 \pm 0.05 \mathrm{~s}^{-1}$ for saline and $0.29 \pm 0.02 \mathrm{~s}^{-1}$ for DOX $\left(t_{13}=3.25 ; p=0.01\right.$; Figure $\left.2 \mathrm{~B}\right)$. However, no significant change in mean uptake rate constant in the DG of the hippocampus was measured, with uptake rate constants of $0.36 \pm 0.05 \mathrm{~s}^{-1}$ for saline and $0.26 \pm 0.07 \mathrm{~s}^{-1}$ for DOX-treated mice $\left(\mathrm{t}_{11}=1.57 ; \mathrm{p}=0.15\right.$; Figure $2 \mathrm{C})$.

A repeated measures two-way ANOVA on $\mathrm{T}_{80}$ measures at various depths in the $\mathrm{FC}$ did not identify a treatment effect $(F(1,9)=2.72 ; p=0.13$; Figure 3A). Also, no differences were detected when the $\mathrm{T}_{80 \mathrm{~s}}$ for each depth was averaged to a single point per animal (saline: $2.3 \pm 0.1$ seconds, DOX: $3.2 \pm 0.4$ seconds; $\mathrm{t}_{13}=1.63 ; \mathrm{p}=0.13$; $\mathrm{n}=3$ /group; Figure $3 \mathrm{~B}$ ).

However, in the DG, the clearance time was increased by $48 \%$ in the DOX-treated group; with saline-treated mice clearing $80 \%$ of glutamate in $2.9 \pm 0.2$ seconds and DOX-treated mice taking $4.3 \pm 0.4$ seconds $\left(\mathrm{t}_{11}=2.83 ; \mathrm{p}=0.02\right.$; Figure $\left.3 \mathrm{D}\right)$. Taken together, these data indicate that DOX treatment results in decreased clearance parameters of glutamate in the FC and DG.

\subsection{KCl-evoked Glutamate Overflow in the FC and DG}

To evaluate the effect of DOX on evoked release of glutamate, local applications of an isotonic $\mathrm{KCl}$ solution were used to depolarize terminals in the FC and DG. Similar volumes of $\mathrm{KCl}(\sim 50-75 \mathrm{nl})$ elicited reproducible releases of glutamate (Figure 4C), which were compared between DOX-treated and control mice. Potassium-evoked glutamate overflow in the averaged depths of the FC was not significantly increased in saline treated mice $(10.85 \pm 2.5 \mu \mathrm{M})$ as compared to in DOX-treated mice $(15.68 \pm 3.0 \mu \mathrm{M})\left(\mathrm{t}_{12}=1.24 ; \mathrm{p}=0.24\right.$; 
Figure 4A). In the DG, $\mathrm{KCl}$-evoked glutamate overflow was significantly greater in DOX

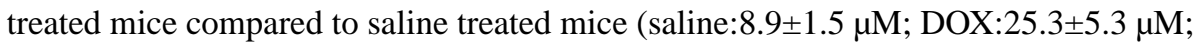
$\mathrm{t}_{13}=2.77 ; \mathrm{p}=0.02$; Figure 4B). Thus, local application of $\mathrm{KCl}$ elicited reproducible release of glutamate in the FC and DG (Figure 4C); however it was only significantly altered in the DG of DOX treated mice.

\subsection{Cognitive function as measured in the Morris Water Maze test}

The MWM test was used as an assessment of cognitive function in mice treated with either Saline or DOX. A repeated measures two-way ANOVA revealed no significant changes in distance traveled to the platform over time as a function of DOX treatment $(F(1,12)=0.83$; $\mathrm{p}=0.38$; Figure $5 \mathrm{~A}$ ). However, both swim speed and time to platform changed as a function of DOX treatment over time. With swim speed of DOX, treated animals were slower than controls $(F(1,12)=10.04 ; p=0.008$; Figure $5 \mathrm{~B})$ and consequently took longer to find the platform $(\mathrm{F}(1,12)=5.15 ; \mathrm{p}=0.04$; Figure $5 \mathrm{C})$. A post-hoc multiple comparison of swim speed over time indicated the most profound impact of DOX was over the first 2 days following treatment. These data indicated that DOX significantly decreased the speed at which the mice traveled, but the overall distance to the platform was not impacted.

\subsection{Discussion}

These experiments evaluated the effect of a single, acute DOX treatment on glutamate neurotransmission in two anatomical structures integral to normal cognition in mice (frontal cortex and hippocampus). The Morris Water Maze was employed to assess cognitive function. To the best of our knowledge, these are the first studies to directly address the in vivo properties of glutamate neurotransmission following a dose of DOX in the mouse similar to that known to cause cognitive deficits in humans. Our results showed that at $24 \mathrm{~h}$ post-injection, glutamate dynamics were affected in different ways depending of the brain region. Glutamate uptake was $45 \%$ slower in the FC and in the DG, glutamate took $48 \%$ longer to clear than saline-treated mice. $\mathrm{KCl}$-evoked glutamate release was significantly greater in the DG of DOX treated mice, supporting that evoked release of glutamate was impacted by DOX treatment (Stephens et al., 2011). These data support the hypothesis that systemic DOX treatment changes glutamate neurotransmission within $24 \mathrm{~h}$ postadministration. Further, these changes may represent the beginning of alterations to glutamate neurotransmission involved in cognitive circuitry following DOX treatment that may lead to the development of CICI.

DOX-induced slower clearance of glutamate was identified by decreased $\mathrm{k}_{-1}$ in the $\mathrm{FC}$ and a longer $\mathrm{T}_{80}$ in the DG. Changes in glutamate clearance can result from changes in glutamate transporter trafficking, transport capacity, transporter affinity, transcription and translation, and abnormal transporter post-translational modifications (Maragakis and Rothstein, 2004). In these studies, the $\mathrm{k}_{-1}$ best represents the velocity of transporters, whereas the $\mathrm{T}_{80}$ is more representative of affinity for glutamate to the transporter. In all areas of the brain, 80-90\% of glutamate transporters are located on astrocytes (Danbolt, 2001). Previous research in our lab has shown that changes in the surface expression of glutamate transporters can correlate with uptake parameters (Nickell et al., 2007). Thus, a decrease in the surface expression of 
GLAST and/or GLT-1, the predominant glial transporters in rodents, may explain the findings following DOX administration. The effects of DOX on glutamate clearance could also represent an adaptive change to glial elements that alter the regulation of glutamate signaling. This has been seen in our recent work involving an animal model of traumatic brain injury (Hinzman et al., 2012).

From our experience, an increase in $\mathrm{KCl}$-evoked glutamate overflow could represent several alterations: an increase in presynaptic release, output of glutamate from glia, a decreased capacity for glutamate clearance and possible changes in mGluR regulation of glutamate release. Changes in glutamate overflow could also arise from impaired extracellular buffering capacity (Santhakumar et al., 2003) or vesicular loading (high quantal transmitter concentration or more released vesicles) (Watt et al., 2000). GABA-ergic modulation is also important in balancing inhibitory/excitatory signaling, and changes in GABA neurotransmission, receptor number and function could also contribute to increased glutamate overflow (Jacob et al., 2008). Slower glutamate clearance parameters measured in these experiments likely contribute to the increased glutamate overflow in the DG, however, additional pharmacological studies are needed to determine the mechanism(s).

In order to assess cognitive function after DOX treatment, mice were subjected to MWM testing for 5 consecutive days after a single DOX administration by assessing distance traveled, swim speed and time to reach the platform. DOX treatment did not significantly impact the total distance traveled to the platform, only the speed at which the mice were traveling. Slower travel likely results from the single dose DOX causing lethargy, but not necessarily impairing cognitive function. Thus, the changes we are seeing in glutamate regulation may be the beginning of the functional changes that occur following DOX treatment that later culminate in cognitive impairment. This is in keeping with slow changes that are often seen in the cognitive function of cancer survivors who have been treated with DOX (Zimmer et al., 2015).

Currently, data support that DOX does not enter the CNS directly but accumulates outside the blood-brain barrier (Tangpong et al., 2006). Despite DOX's, or its major metabolite's, inability to traverse the blood brain barrier, DOX treatment has been reported to increase tumor necrosis factor-a (TNF) in serum from $1 \mathrm{~h}$ to $24 \mathrm{~h}$ post-injection. TNF could then infiltrate the brain, causing CNS effects by TNF-initiated production of reactive oxygen and nitrogen species (Gaman et al., 2016; Gutierrez et al., 1993; Joshi et al., 2007; Joshi et al., 2010; Keeney et al., 2015; Tangpong et al., 2006; Tangpong et al., 2007). Tangpong et al. provides support for this mechanism by reporting increased levels of TNF in brain homogenates at $3 \mathrm{~h}$ post-injection, heavily localized to neurons in the cortex and hippocampus (Tangpong et al., 2006). Previous studies in rat organotypic hippocampalentorhinal cortex (HEC) brain slice culture suggest that TNF inhibited glutamate clearance through a similar mechanism as the glutamate uptake inhibitors, dihydrokainate (DHK) and trans-pyrrolidine-2,4-dicarboxylic acid (t-PKC) reference (Zou and Crews, 2005). Indirect alterations in glutamate clearance can also arise from oxidative stress; where receptor mediated alterations in glutamate uptake through NF- $\mathrm{kB}$ have been demonstrated (Zou and Crews, 2005). Additionally, TNF has also been shown to inhibit EAAT2 (the human homolog of GLT-1) in primary normal human fetal astrocytes by interacting with 
transcription and EAAT2 promoter activity as well as decreasing mRNA and protein levels (Su et al., 2003). More studies are necessary to delineate mechanisms controlling glutamate transporter disruption after DOX treatment, especially additional studies that address the long-term effects and repeated administration of DOX, which would better mimic the routine clinical usage of DOX in cancer patients.

These data support that the FC and DG of mice are vulnerable to acute treatment with DOX. Clinical studies, using a variety of chemotherapy regimens, have documented long-term treatment-induced deficits in executive function and working memory in cancer survivors (Ahles and Saykin, 2007; Kesler et al., 2011; Saykin et al., 2006). Structural and functional magnetic resonance imaging (MRI) studies report volumetric reductions and reduced activation in the frontal cortex during cognitive tasks (Ahles and Saykin, 2007; McDonald, 2011; Saykin et al., 2006). Functional MRI of patients during tasks testing executive function and episodic memory at 10 years post-chemotherapy treatment indicated hypoactivation of the dorsolateral prefrontal cortex and parahippocampal gyrus, while no significant changes in the hippocampus were detected (Note: 5-fluorouracil, epirubicin, cyclophosphamide chemotherapy regimen were administered in these experiments, where epirubicin, like DOX, is an anthracycline with similar mechanisms of action) (de Ruiter et al., 2011). In a study with monozygotic twins, where one was treated with a regimen including DOX, hyperactivation of the frontal cortex and parietal cortex were apparent in the DOX-treated twin in a functional MRI testing working memory; however performance accuracy was similar (Ferguson et al., 2007). Taken together, these studies support the idea that the FC and DG are susceptible to long-term deficits as a result of chemotherapy treatment (DOX and alternative anthracyclines).

Taken together, these data support the hypothesis that systemic DOX treatment results in changes in glutamate neurotransmission in key memory areas within $24 \mathrm{~h}$, without a lasting impact on spatial learning and memory. The DOX dose used in these studies was similar to the maximum single clinical therapeutic dose, supporting that these studies likely have relevance to the clinical usage of DOX. Additional studies are needed as understanding the functional effects of DOX on glutamate neurotransmission may help us understand and prevent some of the debilitating side effects of chemotherapeutic treatment in cancer survivors.

\subsection{Experimental Procedures}

\subsection{Subjects}

Male B6C3F1J mice ( $\sim 2$ months; $~ 28$ grams; $\mathrm{n}=30$ ) were obtained from The Jackson Laboratory (Bar Harbor, ME), group-housed (2-4 per cage) with unlimited access to food and water, and maintained on a twelve-hour light/dark cycle (lights on at $0600 \mathrm{hrs).}$ Protocols for animal use were approved by the Institutional Animal Care and Use Committee (IACUC), which is Association for Assessment and Accreditation of Laboratory Animal Care International approved, and all procedures were carried out in accordance with the National Institutes of Health Guide for Care and Use of Laboratory Animals. 


\subsection{Doxorubicin Treatment}

Mice were weighed and given an intraperitoneal (i.p.) injection of $25 \mathrm{mg} / \mathrm{kg}$ of DOX (doxorubicin hydrochloride, Ben Venue Laboratories, Inc. Bedford, OH 44146; $2 \mathrm{mg} / \mathrm{ml}$ in saline; NDC 55390-237-01) or an equivalent volume of saline. The DOX dose used was similar to the maximum single clinical therapeutic dose $\left(60-75 \mathrm{mg} / \mathrm{m}^{2}\right.$ ) (see (Gilliam et al., 2009; Piscitelli et al., 1993)) calculated according to the conversion factor previously described (Freireich et al., 1966). The $\mathrm{pH}$ of saline and DOX were adjusted to 3 using hydrochloric acid (Bosanquet, 1986). Twenty-four-hours after injection, mice were prepared for amperometric recordings of glutamate neurotransmission and spatial learning and memory testing using the Morris Water Maze.

\subsection{Surgeries for Amperometric Recordings of Glutamate}

Mice were weighed and anesthetized using i.p. injections of 10\% urethane solution (1.25 g/ $\mathrm{kg}$ ). They were placed in a stereotaxic frame (David Kopf Instruments, Tujunga, CA) fitted with a Cunningham ${ }^{\mathrm{TM}}$ Mouse and Neonatal Rat Adaptor (Stoelting Co., Wood Dale, IL). A circulating heating pad (Gaymar Industries, Inc., Orchard Park, NY) coupled to a rectal temperature probe (Yellow Spring Instrument Co., Yellow Springs, $\mathrm{OH}$ ) was used to maintain body temperature at $37^{\circ} \mathrm{C}$. After a midline scalp incision, the skin and fascia were reflected and a bilateral miniature craniotomy over the hippocampus and frontal cortex was completed. A miniature $\mathrm{Ag} / \mathrm{AgCl}$ reference electrode was placed in a posterior subcutaneous pocket formed using blunt dissection and held in position by sutures (Moussy and Harrison, 1994; Quintero et al., 2007).

\subsection{Amperometry}

4.4.1 In vivo Electrochemical Recordings-The MEAs are capable of recording realtime extracellular glutamate signaling with low limits of detection $(\sim 0.2-1.5 \mu \mathrm{M})$ and high spatial resolution (Pt site: $333 \times 15 \mu \mathrm{m}$ ) with minimal damage to the surrounding tissue (50-100 $\mu \mathrm{m}$ ) (Burmeister et al., 2002; Hascup et al., 2009). The capability of the MEAs to be moved in the dorsal to ventral axis between measurements provided recordings in the 3 layers of the FC (cingulate, infralimbic and limbic cortices) and the capability to assess the structure in its entirety by averaging the recording sites. The In vivo amperometric recording procedures are similar to our previously published methods (Hinzman et al., 2010; Thomas et al., 2009). Constant voltage amperometry was performed using a FAST-16 Mk-II electrochemistry instrument (Quanteon, L.L.C., Nicholasville, KY) using software (Fast Analytical Sensor Technology (FAST), Quanteon, L.L.C.,) developed for concurrent fourchannel recordings. A potential of $+0.7 \mathrm{~V}$ was applied versus a $\mathrm{Ag} / \mathrm{AgCl}$ reference electrode and the data were recorded at a final display frequency of $2 \mathrm{~Hz}$. Current signals were converted to voltage by the headstage $(2 \mathrm{pA} / \mathrm{mV})$.

4.4.2 Microelectrode Array Preparation-Ceramic-based MEAs that contained 4 platinum $(\mathrm{Pt})$ recording sites $(15 \mu \mathrm{m} \times 333 \mu \mathrm{m})$ in a paired configuration were prepared to measure glutamate. These microelectrodes were fabricated and selected for in vivo recordings using published methods (Burmeister et al., 2000; Burmeister et al., 2002; Thomas et al., 2009). Pt sites 1 and 2 were coated with a solution containing glutamate 
oxidase (GluOx), bovine serum albumin (BSA) and glutaraldehyde, enabling these sites to selectively detect glutamate levels with low limits of detection (Nickell et al., 2005). Pt sites 3 and 4 were coated with only BSA and glutaraldehyde and served as sentinels, recording everything channels 1 and 2 record except for glutamate (Burmeister and Gerhardt, 2001; Day et al., 2006). All 4 recording sites were electroplated with a size-exclusion layer, 1,3phenylenediamine (mPD) prior to calibration and use in vivo (Thomas et al., 2009). GluOx converts glutamate into a-ketoglutarate and peroxide $\left(\mathrm{H}_{2} \mathrm{O}_{2}\right)$. The $\mathrm{H}_{2} \mathrm{O}_{2}$, the reporter molecule, traverses the mPD layer and is readily oxidized and recorded as current using the FAST-16 instrument.

For calibration, the microelectrode tip was submerged in $40 \mathrm{ml}$ of $0.05 \mathrm{M}$ PBS (pH 7.1-7.4), maintained at $37^{\circ} \mathrm{C}$ using a circulating water bath (Gaymar Industries, Inc., Orchard Park, NY) that was stirred using a magnetic stir bar and battery operated stir plate (Barnart Co.). Following 20 minutes of equilibration, aliquots of stock solutions in the amount of $500 \mu \mathrm{l}$ ascorbic acid (AA; $20 \mathrm{mM})$, three $40 \mu \mathrm{l}$ aliquots of L-glutamate $(20 \mathrm{mM}), 40 \mu \mathrm{l}$ dopamine (2 $\mathrm{mM})$, and $40 \mu \mathrm{H}_{2} \mathrm{O}_{2}(8.8 \mathrm{mM})$ were added to the PBS to calibrate the MEA to produce final concentrations of $250 \mu \mathrm{M}$ AA, 20, 40 and $60 \mu \mathrm{M}$ glutamate, $2 \mu \mathrm{M}$ dopamine, and 8.8 $\mu \mathrm{M} \mathrm{H}_{2} \mathrm{O}_{2}$; a representative recording of an in vitro calibration can be found in Figure $2 \mathrm{~B}$ of (Thomas et al., 2009). From the calibration, the slope (electrode sensitivity to L-glutamate), selectivity (selectivity for recording glutamate over AA), and limit of detection (LODsmallest amount of detectable glutamate) were determined; average values for slope were $7.6 \pm 0.4 \mathrm{pA} / \mu \mathrm{M}$, selectivity averaged $98 \pm 11$ to 1 , and LOD (S/N of 3) averaged $1.2 \pm 0.2 \mu \mathrm{M}$ ( $\mathrm{n}=44$ electrodes; 81 glutamate recording sites). Calibrations were performed prior to experiments as MEA performance is not significantly compromised as a result of implantation (Hinzman et al., 2010).

After the MEA was calibrated, a single barrel glass capillary with filament $\left(1.0 \times 0.58 \mathrm{~mm}^{2}\right.$, 6", A-M Systems, Inc.) was pulled using a Kopf Pipette Puller (Model 720 David Kopf Instruments, Tujunga, CA). The pulled micropipette was bumped against a glass rod so that the inner diameter of the micropipette was $10-14 \mu \mathrm{m}$ (average $=12 \mu \mathrm{m}$ ). Clay was used to place the tip of the micropipette between the 4 Pt recording sites, approximately $50-75 \mu \mathrm{m}$ (average $=73 \mu \mathrm{m}$ ) away from the MEA surface. This alignment was secured using Sticky Wax (Kerr Manufacturing Co). The measurements were taken under a microscope with a calibrated reticule.

4.4.3 In vivo Experimental Protocol for Measurements of Glutamate-Prior to in vivo placement of the MEA-micropipette assembly, the micropipette was filled with $200 \mu \mathrm{M}$ glutamate $(200 \mu \mathrm{M}$ L-glutamate in $0.9 \%$ physiological saline; $\mathrm{pH}=7.2-7.4)$ or isotonic 70 $\mathrm{mM}$ potassium $(\mathrm{KCl})$ solution $\left(70 \mathrm{mM} \mathrm{KCl}, 79 \mathrm{mM} \mathrm{NaCl}, 2.5 \mathrm{mM} \mathrm{CaCl}_{2} ; \mathrm{pH}=7.2-7.4\right)$ using a combination of a $1 \mathrm{ml}$ syringe, a $0.22 \mu \mathrm{m}$ sterile syringe filter (Costar Corporation), and a $4^{\prime \prime}$ stainless steel needle (30 gauge, beveled tip; Popper and Son, Inc., NY). The MEA- micropipette assembly was positioned in the brain according to stereotaxic coordinates, where all anterior-posterior (AP) measures were from bregma, medial-lateral (ML) measures were from midline and dorsal-ventral (DV) measures were from the dural surface (FC: $+2.0, \pm 0.5-1.0,-1.5-2.5 \mathrm{~mm}, \sim 8^{\circ}$ angle toward midline; DG: $-2.5, \pm 1.3,-2.1$ mm; Figure 1A) (Paxinos and Franklin, 2001). 
Nanoliter volumes of glutamate or $\mathrm{KCl}$ were locally applied to the extracellular space of the mouse brain by pressure ejection, using a Picospritzer II (Parker Hannifin Corp., General Valve Corporation). Pressure was applied at 5-25 psi for 1 second in all experiments. The volume of glutamate or $\mathrm{KCl}$ delivered was measured by determining the amount of fluid ejected from the micropipette using a dissection microscope fitted with a calibrated reticule (Cass et al., 1992; Friedemann and Gerhardt, 1992).

4.4.4 In vivo Measurements of Glutamate Clearance-Upon stereotaxic placement of the MEA-micropipette assembly, 10-20 minutes of baseline data were recorded in the FC and DG. The microelectrode was then moved in $500 \mu \mathrm{m}$ increments in the FC using a micromanipulator (MO-10; Narishige Scientific Instruments, Tokyo, Japan) and allowed to return to baseline for approximately 10 minutes between depths. Only one recording location was feasible in the DG due to size constraints.

For glutamate uptake experiments, once a steady-state signal was achieved, the exogenous glutamate solution was locally applied every 30-60 seconds for a total of 5 ejections. Parameters from 3 signals ranging from 5-20 $\mu \mathrm{M}$ in amplitude were averaged for each $\mathrm{Pt}$ electrode site at each depth. The each recording was analyzed for the uptake rate constant $\left(\mathrm{k}_{-1}\right)$ and the time it took for $80 \%$ of the signal to decay from maximum amplitude $\left(\mathrm{T}_{80}\right)$ (Figure 1B). Amplitude-matched signals from DOX-treated mice were compared to controls (Hascup et al., 2006; Thomas et al., 2009). Most glutamate measures from the paired microelectrode recording sites were averaged to a single point per depth.

For potassium $(\mathrm{KCl})$-evoked glutamate release, a steady-state signal was first achieved. Then the effects of a single local application of $\mathrm{KCl}$ solution on glutamate release were determined (Gerhardt et al., 1985; Thomas et al., 2009). The maximum amplitude was compared between saline- and DOX-treated mice (Figure 1B; amplitude illustrated). Data regarding amperometric recordings were volume-matched prior to data analysis.

4.4.5 MEA Placement Verification-After experiments, animals used for in vivo electrochemistry were overdosed with sodium pentobarbital $(150 \mathrm{mg} / \mathrm{kg}$; i.p.) and transcardially perfused with $0.9 \%$ saline followed by $4 \%$ paraformaldehyde. Electrode tracks were identified and registered with a standard mouse brain atlas to confirm MEA placement. No animals were excluded due to electrode misplacement.

4.4.6 Statistical Analysis of Amperometric Recordings-Data from the paired recording sites on the MEA were averaged and used as a single data point. If only one microelectrode site provided usable data, then the recordings were incorporated from a single site. Multiple depths within anatomical regions of the FC were included as distinct regions in a repeated measures two-way ANOVA (with treatment and depth as factors), as well as averaged for determination of differences in the whole anatomical structure (2-tailed Student's t-test). Numbers of animals differed between groups for a variety of reasons; electrode recording failure due to blood contacting the microelectrode, loss of exclusion layer (mPD) as indicated by the sentinel channels and outlier status (using Grubb's test). In all cases, significance was defined as $\mathrm{p}<0.05$. 


\subsection{Morris Water Maze (MWM)}

Eight-week-old male B6C3 mice (25-30 g) were randomly assigned to two groups and were injected with a single i.p. treatment with doxorubicin hydrochloride, $20 \mathrm{mg} / \mathrm{kg}(\mathrm{N}=8)$, or the same volume of saline as control $(\mathrm{N}=6)$. On the following 5 days, the mice were given 3 daily trials with an inter-trial interval of $10 \mathrm{~min}$ in the presence of the platform. All cognitive tests were performed in a $100 \mathrm{~cm}$ (diameter) tank filled with water opacified by the addition of nontoxic paint. The water was kept at $24 \pm 1^{\circ} \mathrm{C}$ and surrounded by dark walls containing geometric designs that served as distal visual cues. During acquisition, each animal was allowed a maximum of $60 \mathrm{~s}$ to find the submerged platform. After $60 \mathrm{~s}$, mice that did not find the escape platform were physically guided to it and allowed to remain on the platform for $30 \mathrm{~s}$. The path length, time and speed of the mice were recorded by a computer-based video tracking system (HVS Image Analysis VP-200, HVS Image, Hampton, UK). Data were analyzed offline by using HVS Image, and processed with Microsoft EXCEL. Data were analyzed using a repeated measures two-way ANOVA (factors: treatment type and time after single injection) with Bonferroni's multiple comparison tests.

\section{Acknowledgments}

The authors would like to thank the technical expertise of Peter Huettl for help with maintenance of the FAST systems and Verda Davis for electrode preparation. This work was supported by a postdoctoral fellowship to Theresa Currier Thomas (T32 AG000242), the University of Kentucky Markey Cancer Center and College of Medicine, grant number UL1RR033173 from the National Center for Research Resources (NCRR), the Office of the Director, National Institutes of Health (NIH) and supported by the NIH Roadmap for Medical Research, NIH CA 139843 and CA 139844. The content is solely the responsibility of the authors and does not necessarily represent the official views of NCRR and NIH.

\section{References}

Ahles TA, et al. Neuropsychologic impact of standard-dose systemic chemotherapy in long-term survivors of breast cancer and lymphoma. J Clin Oncol. 2002; 20:485-493. [PubMed: 11786578]

Ahles TA, Saykin AJ. Candidate mechanisms for chemotherapy-induced cognitive changes. Nat Rev Cancer. 2007; 7:192-201. [PubMed: 17318212]

Aluise $\mathrm{CD}$, et al. Chemo brain (chemo fog) as a potential side effect of doxorubicin administration: role of cytokine-induced, oxidative/nitrosative stress in cognitive dysfunction. Adv Exp Med Biol. 2010; 678:147-156. [PubMed: 20738017]

Aluise CD, et al. -Mercaptoethane sulfonate prevents doxorubicin-induced plasma protein oxidation and TNF-alpha release: Implications for the reactive oxygen species-mediated mechanisms of chemobrain. Free Radic Biol Med. 2011:2.

Bosanquet AG. Stability of solutions of antineoplastic agents during preparation and storage for in vitro assays. II. Assay methods, adriamycin and the other antitumour antibiotics. Cancer Chemother Pharmacol. 1986; 17:1-10. [PubMed: 2421936]

Burmeister JJ, Moxon K, Gerhardt GA. Ceramic-based multisite microelectrodes for electrochemical recordings. Anal Chem. 2000; 72:187-192. [PubMed: 10655652]

Burmeister JJ, Gerhardt GA. Self-referencing ceramic-based multisite microelectrodes for the detection and elimination of interferences from the measurement of L-glutamate and other analytes. Anal Chem. 2001; 73:1037-1042. [PubMed: 11289414]

Burmeister JJ, et al. Improved ceramic-based multisite microelectrode for rapid measurements of Lglutamate in the CNS. J Neurosci Methods. 2002; 119:163-171. [PubMed: 12323420]

Cass WA, et al. Differences in dopamine clearance and diffusion in rat striatum and nucleus accumbens following systemic cocaine administration. J Neurochem. 1992; 59:259-266. [PubMed: 1613502] 
Danbolt NC. Glutamate uptake. Prog Neurobiol. 2001; 65:1-105. [PubMed: 11369436]

Day BK, et al. Microelectrode array studies of basal and potassium-evoked release of L-glutamate in the anesthetized rat brain. J Neurochem. 2006; 96:1626-1635. [PubMed: 16441510]

de Ruiter MB, et al. Cerebral hyporesponsiveness and cognitive impairment 10 years after chemotherapy for breast cancer. Hum Brain Mapp. 2011; 32:1206-19. [PubMed: 20669165]

Ferguson RJ, et al. Brain structure and function differences in monozygotic twins: possible effects of breast cancer chemotherapy. J Clin Oncol. 2007; 25:3866-70. [PubMed: 17761972]

Freireich EJ, et al. Quantitative comparison of toxicity of anticancer agents in mouse, rat, hamster, dog, monkey, and man. Cancer Chemother Rep. 1966; 50:219-44. [PubMed: 4957125]

Friedemann MN, Gerhardt GA. Regional effects of aging on dopaminergic function in the Fischer-344 rat. Neurobiol Aging. 1992; 13:325-332. [PubMed: 1522947]

Gaman AM, et al. The Role of Oxidative Stress in Etiopathogenesis of Chemotherapy Induced Cognitive Impairment (CICI)-“Chemobrain”. Aging Dis. 2016; 7:307-17. [PubMed: 27330845]

Gerhardt G, et al. Dopaminergic neurotoxicity of 1-methyl-4-phenyl-1,2,3,6-tetrahydropyridine (MPTP) in the mouse: an in vivo electrochemical study. J Pharmacol Exp Ther. 1985; 235:259265. [PubMed: 2864435]

Gilliam LA, et al. Doxorubicin acts through tumor necrosis factor receptor subtype 1 to cause dysfunction of murine skeletal muscle. J Appl Physiol. 2009; 1985; 107:1935-42. [PubMed: 19779154]

Gutierrez EG, Banks WA, Kastin AJ. Murine tumor necrosis factor alpha is transported from blood to brain in the mouse. J Neuroimmunol. 1993; 47:169-176. [PubMed: 8370768]

Hascup ER, et al. Histological studies of the effects of chronic implantation of ceramic-based microelectrode arrays and microdialysis probes in rat prefrontal cortex. Brain Res. 2009; 1291:1220. [PubMed: 19577548]

Hascup, KN., et al. Second-by-second measures of l-glutamate and other neurotransmitters using microelectrode arrays. In: Michael, AC., Borland, LM., editors. Electrochemical Methods for Neuroscience. CRC Press; Boca Raton, FL: 2006. p. 407-450.

Hinzman JM, et al. Diffuse brain injury elevates tonic glutamate levels and potassium-evoked glutamate release in discrete brain regions at two days post-injury: an enzyme-based microelectrode array study. J Neurotrauma. 2010; 27:889-899. [PubMed: 20233041]

Hinzman JM, et al. Disruptions in the regulation of extracellular glutamate by neurons and glia in the rat striatum two days after diffuse brain injury. J Neurotrauma. 2012; 29:1197-208. [PubMed: 22233432]

Jacob TC, Moss SJ, Jurd R. GABA(A) receptor trafficking and its role in the dynamic modulation of neuronal inhibition. Nature Reviews Neuroscience. 2008; 9:331-343. [PubMed: 18382465]

Joshi G, et al. Glutathione elevation by gamma-glutamyl cysteine ethyl ester as a potential therapeutic strategy for preventing oxidative stress in brain mediated by in vivo administration of adriamycin: Implication for chemobrain. J Neurosci Res. 2007; 85:497-503. [PubMed: 17171703]

Joshi G, et al. Alterations in brain antioxidant enzymes and redox proteomic identification of oxidized brain proteins induced by the anti-cancer drug adriamycin: implications for oxidative stressmediated chemobrain. Neuroscience. 2010; 166:796-807. [PubMed: 20096337]

Keeney JTR, et al. Superoxide induces protein oxidation in plasma and TNF-alpha elevation in macrophage culture: Insights into mechanisms of neurotoxicity following doxorubicin chemotherapy. Cancer Letters. 2015; 367:157-161. [PubMed: 26225838]

Kesler, SR., et al. International Conference on the Side Effects of Cancer, Chemo Brain: Mechanisms and Assessments. Chemo Brain: Mechanisms \& Assessments; Lexington, KY USA: 2011. Elevated prefrontal cortex myo-inositol and choline in breast cancer survivors at long-term followup (Poster Abstract \#12).

Maragakis NJ, Rothstein JD. Glutamate transporters: animal models to neurologic disease. Neurobiol Dis. 2004; 15:461-473. [PubMed: 15056453]

McDonald, BC. International Conference on the Side Effects of Cancer, Chemo Brain: Mechanisms and Assessments. Chemo Brain: Mechanisms \& Assessments; Lexington, KY USA: 2011. Brain imaging to study mechanisms of chemotherapy-induced cognitive changes (Presenter's Abstract). 
Moussy F, Harrison DJ. Prevention of the rapid degradation of subcutaneously implanted $\mathrm{Ag} / \mathrm{AgCl}$ reference electrodes using polymer coatings. Anal Chem. 1994; 66:674-679. [PubMed: 8154589]

Nickell J, et al. Age-related changes in the dynamics of potassium-evoked L-glutamate release in the striatum of Fischer 344 rats. J Neural Transm. 2005; 112:87-96. [PubMed: 15599607]

Nickell J, et al. Reduced plasma membrane surface expression of GLAST mediates decreased glutamate regulation in the aged striatum. Neurobiol Aging. 2007; 28:1737-1748. [PubMed: 16959378]

Paxinos, G., Franklin, KBJ. The mouse brain in stereotaxic coordinates. 2nd. Academic Press; San Diego: 2001.

Piscitelli SC, et al. Pharmacokinetics and pharmacodynamics of doxorubicin in patients with small cell lung cancer. Clin Pharmacol Ther. 1993; 53:555-61. [PubMed: 8387903]

Pribiag H, Stellwagen D. TNF-alpha downregulates inhibitory neurotransmission through protein phosphatase 1-dependent trafficking of GABA(A) receptors. J Neurosci. 2013; 33:15879-93. [PubMed: 24089494]

Quintero JE, et al. Amperometric measures of age-related changes in glutamate regulation in the cortex of rhesus monkeys. Exp Neurol. 2007; 208:238-246. [PubMed: 17927982]

Raffa, RB., Tallarida, RJ. Chemo Fog: Cancer Chemotherapy-Related Cognitive Impariment. Vol. 678. Landes Bioscience and Springer Science+Business Media; LCC, Austin, Texas and New York, New York: 2010.

Santello M, Bezzi P, Volterra A. TNFalpha controls glutamatergic gliotransmission in the hippocampal dentate gyrus. Neuron. 2011; 69:988-1001. [PubMed: 21382557]

Santello M, Volterra A. TNFalpha in synaptic function: switching gears. Trends Neurosci. 2012; 35:638-47. [PubMed: 22749718]

Santhakumar V, et al. Post-traumatic hyperexcitability is not caused by impaired buffering of extracellular potassium. J Neurosci. 2003; 23:5865-5876. [PubMed: 12843291]

Saykin AJ, et al. Altered Brain Activation Following Systemic Chemotherapy for Breast Cancer: Interim Analysis from a Prospective fMRI Study. J Int Neuropsychol Soc. 2006; 12:131.

Stellwagen D, et al. Differential regulation of AMPA receptor and GABA receptor trafficking by tumor necrosis factor-alpha. J Neurosci. 2005; 25:3219-28. [PubMed: 15788779]

Stephens ML, et al. Age-related changes in glutamate release in the CA3 and dentate gyrus of the rat hippocampus. Neurobiol Aging. 2011; 32:811-20. [PubMed: 19535175]

$\mathrm{Su} \mathrm{ZZ}$, et al. Insights into glutamate transport regulation in human astrocytes: cloning of the promoter for excitatory amino acid transporter 2 (EAAT2). Proc Natl Acad Sci U S A. 2003; 100:19551960. [PubMed: 12578975]

Tangpong J, et al. Adriamycin-induced, TNF-alpha-mediated central nervous system toxicity. Neurobiol Dis. 2006; 23:127-139. [PubMed: 16697651]

Tangpong J, et al. Adriamycin-mediated nitration of manganese superoxide dismutase in the central nervous system: insight into the mechanism of chemobrain. J Neurochem. 2007; 100:191-201. [PubMed: 17227439]

Thomas TC, et al. Decreased dopamine D4 receptor expression increases extracellular glutamate and alters its regulation in mouse striatum. Neuropsychopharmacology. 2009; 34:436-445. [PubMed: 18536704]

Thomas TC, et al. Hypersensitive glutamate signaling correlates with the development of late-onset behavioral morbidity in diffuse brain-injured circuitry. Journal of neurotrauma. 2012; 29:187-200. [PubMed: 21939393]

Watt AJ, et al. Activity coregulates quantal AMPA and NMDA currents at neocortical synapses. Neuron. 2000; 26:659-670. [PubMed: 10896161]

Wefel JS, et al. 'Chemobrain' in breast carcinoma?: a prologue. Cancer. 2004; 101:466-475. [PubMed: 15274059]

Yirmiya R, Goshen I. Immune modulation of learning, memory, neural plasticity and neurogenesis. Brain Behav Immun. 2011; 25:181-213. [PubMed: 20970492]

Zimmer P, et al. Post-chemotherapy cognitive impairment in patients with B-cell non-Hodgkin lymphoma: a first comprehensive approach to determine cognitive impairments after treatment 
with rituximab, cyclophosphamide, doxorubicin, vincristine and prednisone or rituximab and bendamustine. Leuk Lymphoma. 2015; 56:347-52. [PubMed: 24738942]

Zou JY, Crews FT. TNF alpha potentiates glutamate neurotoxicity by inhibiting glutamate uptake in organotypic brain slice cultures: neuroprotection by NF kappa B inhibition. Brain Res. 2005; 1034:11-24. [PubMed: 15713255]

\author{
Abbreviations \\ DOX Doxorubicin \\ FC frontal cortex \\ DG dentate gyrus \\ MEA microelectrode array, $\mathrm{KCl}$, potassium chloride \\ TNF tumor necrosis factor-a \\ GluOX glutamate oxidase
}




\section{Highlights}

- Doxorubicin is a chemotherapeutic agent that impairs cognition in cancer patients

- Cognitive function is mediated by glutamate signaling in the cortex and hippocampus

- In mice, glutamate clearance was slower 24 hours after treatment with doxorubicin

- Doxorubicin increased glutamate release in the hippocampus of mice

- Knowing how doxorubicin impacts brain signaling is pivotal to preventing cognitive side effects 

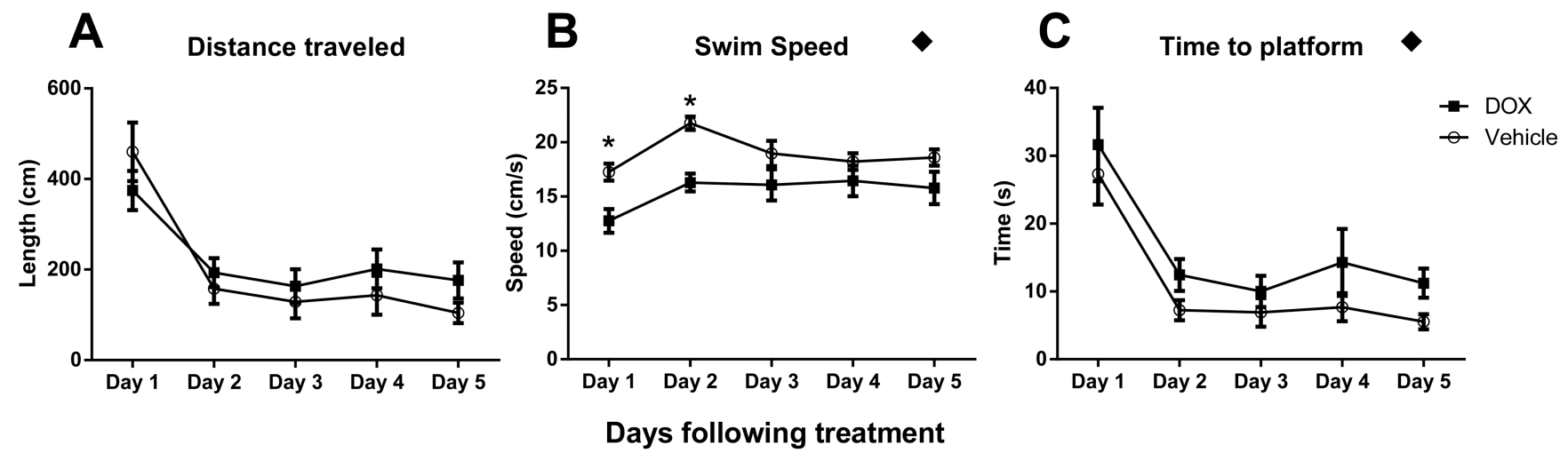

Figure 1.

Twenty-four hours after DOX treatment, glutamate signaling was measured in both hemispheres of the FC and DG of the mouse hippocampus using MEAs. (A) The MEA placement is illustrated in the right hemispheres of the coronal sections (adapted from the mouse brain atlas (Paxinos and Franklin, 2001)). In the FC, recordings were first made in the cingulate $(\mathrm{Cg})$ cortex prior to moving into the prelimbic (PrL), then infralimbic (Il) cortices. The lower coronal section shows the approximate placement of the MEA recording sites in the DG of the hippocampus. (B) The representative in vivo glutamate recording depicts the signaling parameters assessed in these experiments. Extracellular glutamate levels were calculated after the MEA reached a stable baseline (10-20 minutes) by subtracting recordings on the sentinel site from recordings on the glutamate-selective site (containing glutamate oxidase; GluOx). The arrow denotes the local application of exogenous glutamate where detection and subsequent clearance were recorded. Once the maximum amplitude was reached, the uptake rate constant $\left(\mathrm{k}_{-1}\right)$ and $\mathrm{T}_{80}$ (the time required to clear $80 \%$ of the amplitude) were calculated from clearing signal. 


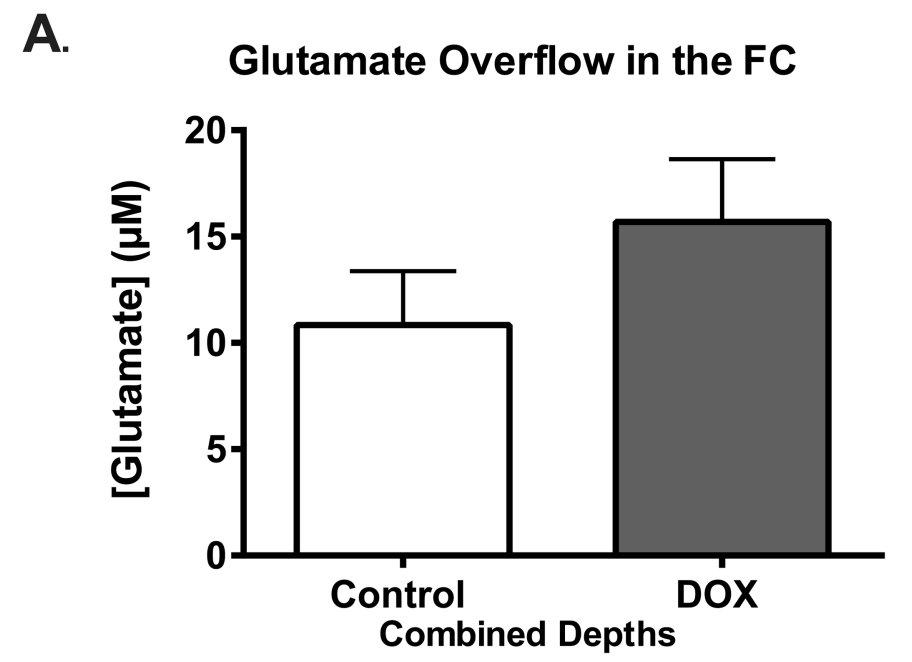

B.
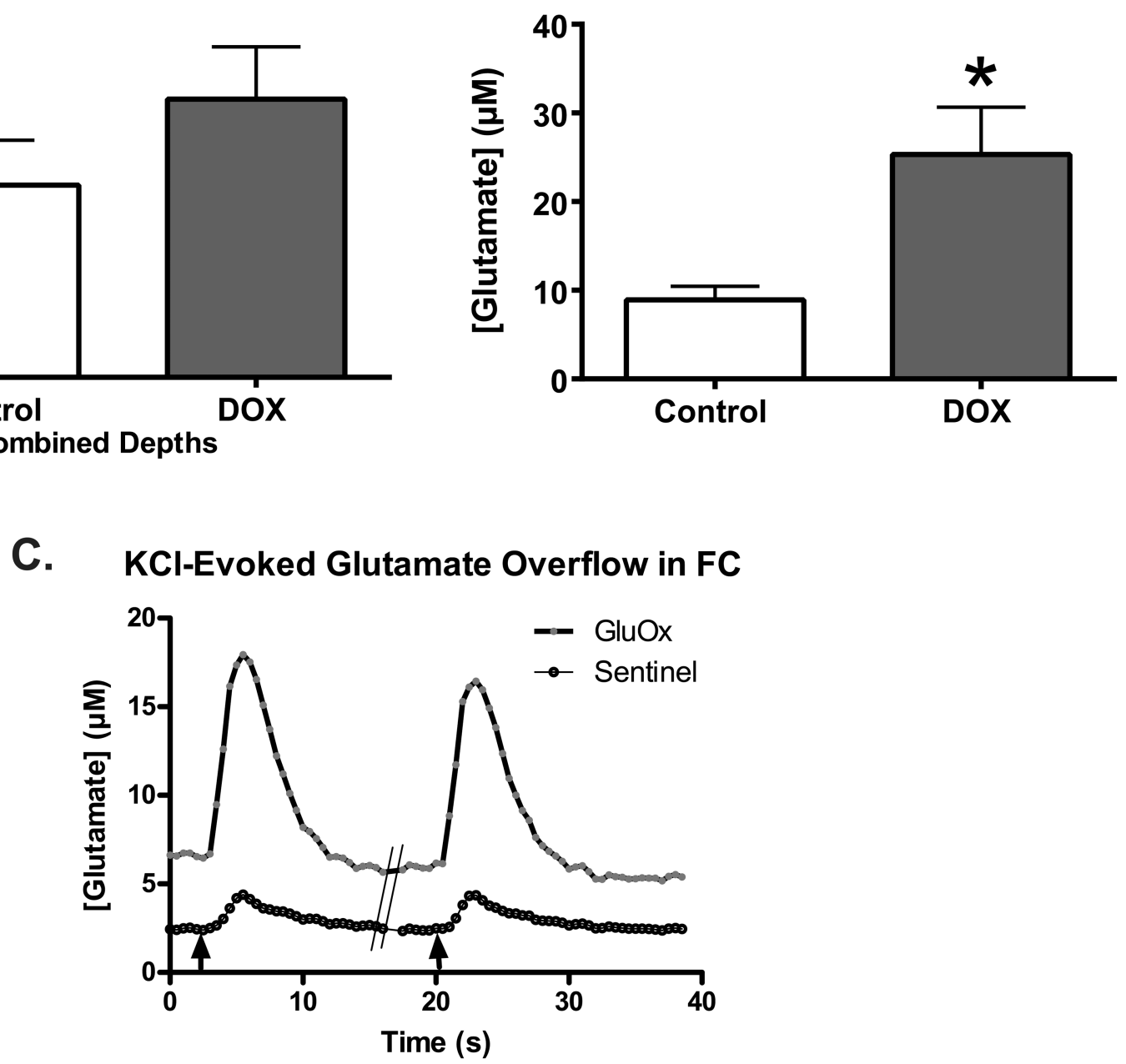

Figure 2.

The uptake rate constant $\left(\mathrm{k}_{-1}\right)$ in the FC is significantly decreased $24 \mathrm{~h}$ after DOX treatment. (A) The depth profile of the $\mathrm{k}_{-1}$ in the FC reveals depth-dependent sensitivity to DOX treatment; especially at the depth of $-2.5 \mathrm{~mm}$, which corresponds to the infralimbic cortex $\left({ }^{*} \mathrm{p}<0.05\right)$. (B) When the depths were averaged, a $45 \%$ decrease of the $\mathrm{k}_{-1}$ in DOX-treated mice is demonstrated in comparison to saline treated animals (Saline $=6, \mathrm{DOX}=9 ; * \mathrm{p}<0.05$ ). (C) In the DG, there were no significant changes in $\mathrm{k}_{-1}$ due to DOX treatment in comparison to saline treatment ( $\mathrm{n}=4$ /group). Statistical analyses were carried out using a RM 2-way ANOVA and a unpaired 2-tailed Student's t-test. Error bars represent the mean \pm SEM. 
A.
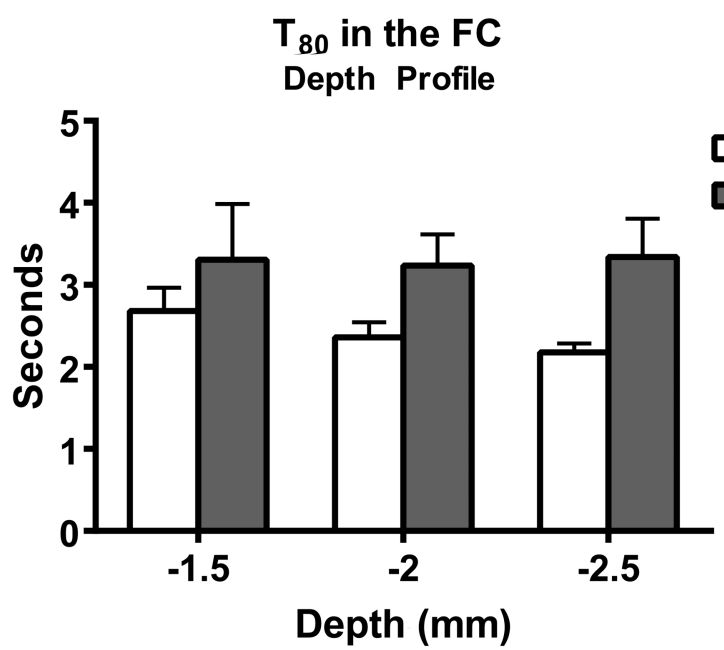

B.

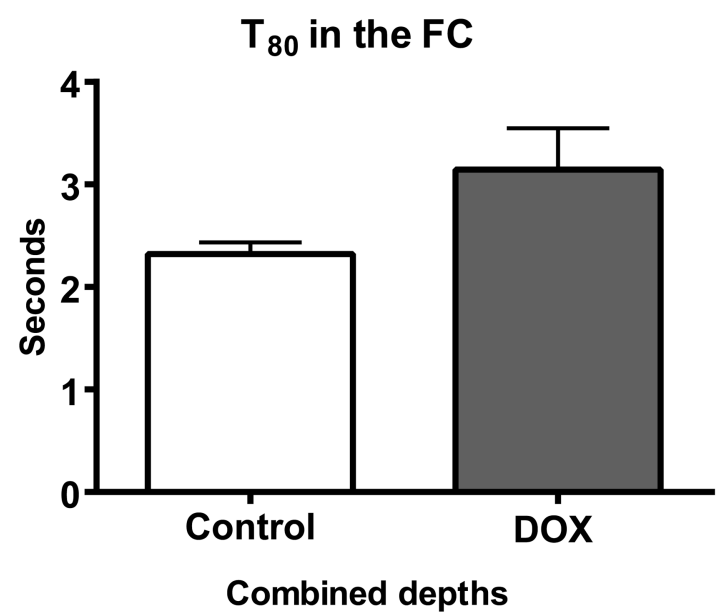

C.

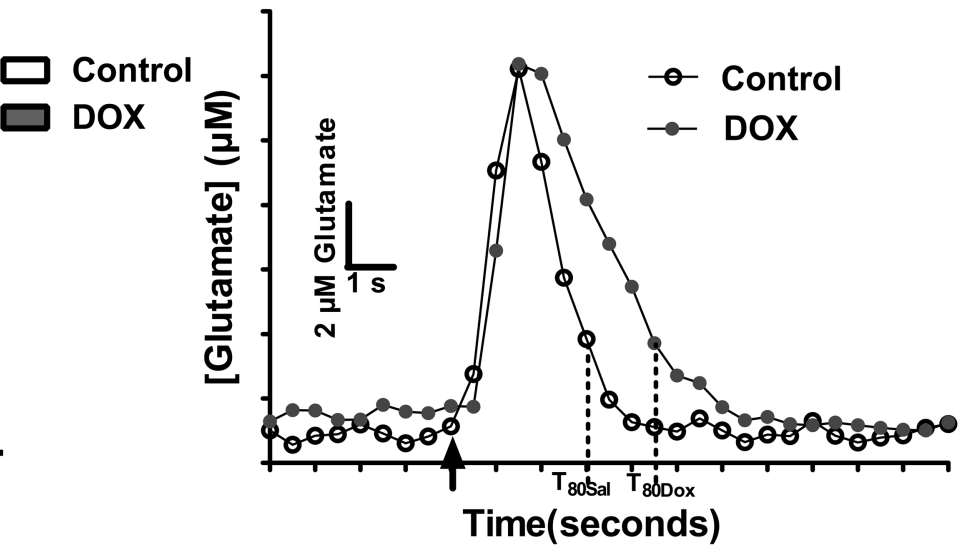

D.

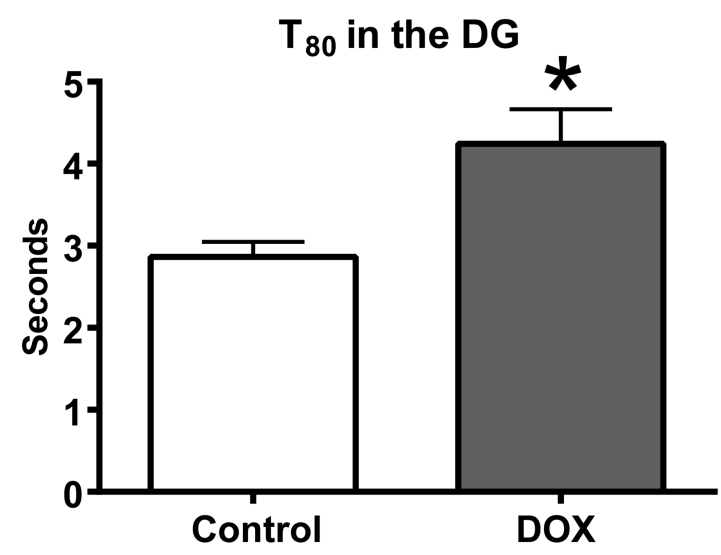

Figure 3.

Clearance times are significantly slower in the DG after DOX treatment. (A) The depth profile of the $\mathrm{T}_{80}$ shows that clearance times as a function of depth and (B) combined to represent the entire region did not differ as a function of treatment $(n=6-9)$. (C) Representative traces (baseline subtracted out) demonstrate the changes in glutamate clearance. The black arrow is where exogenous glutamate was locally applied within the FC. (D) In the DG, a $48 \%$ increase in clearance time as a function of DOX treatment $(\mathrm{n}=7)$ was also measured in comparison to saline treatment $\left(\mathrm{n}=6 ;{ }^{*} \mathrm{p}<0.05\right)$. Statistical analyses were carried out using a 2-way ANOVA and unpaired 2-tailed Student's t-tests. Error bars represent the mean \pm SEM. 
A. Uptake Rate Constant $\left(\mathbf{k}_{-1}\right)$ in the FC

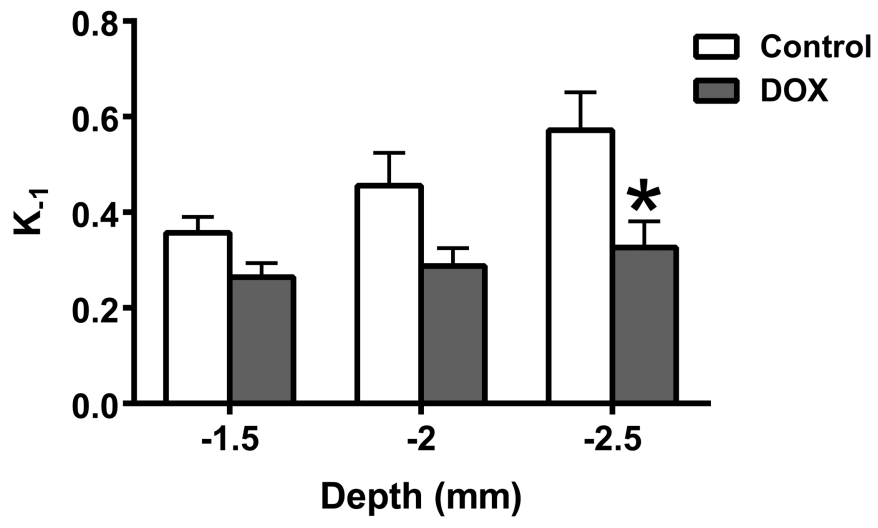

B. Uptake Rate Constant (k-1) FC

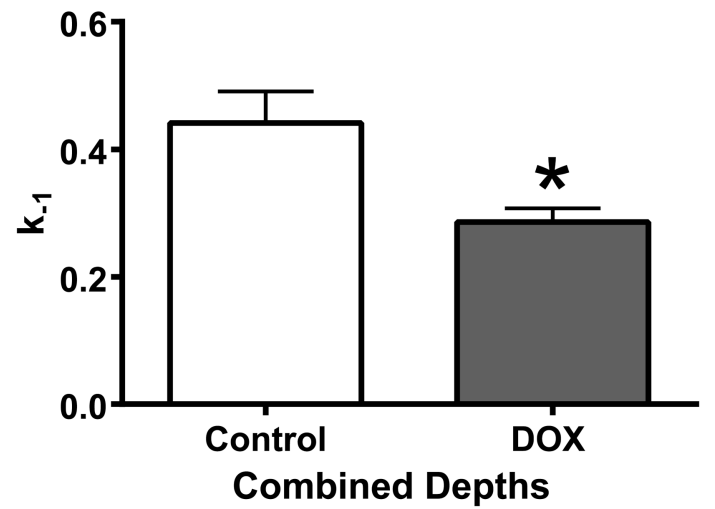

C. Uptake rate constant $\left(k_{-1}\right)$ in the DG

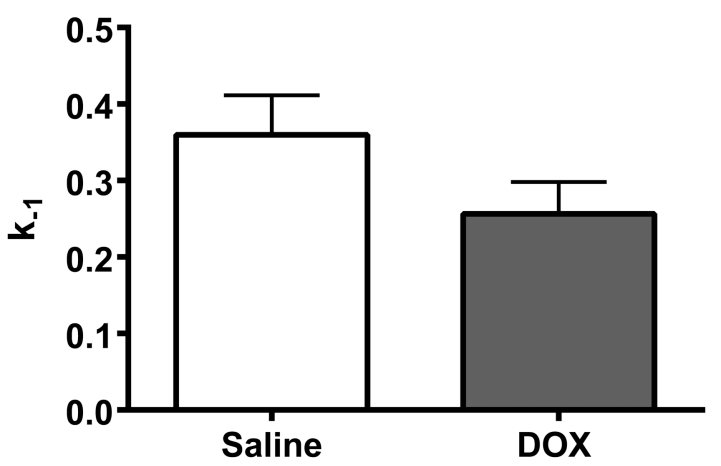

Figure 4.

Potassium-evoked glutamate overflow in increased in the DG of DOX treat mice. (A) No differences in evoked glutamate overflow were evident following DOX treatment in the prefrontal cortex ( $\mathrm{n}=7 /$ group). (B) However, in the $\mathrm{DG}(\mathrm{Sal}=7, \mathrm{DOX}=8$ ), glutamate overflow was significantly greater in DOX treated mice $\left({ }^{*} \mathrm{p}<0.05\right)$. Statistical analysis was done using an unpaired 2-tailed Student's t-test. Error bars represent the mean \pm SEM. (C)

Representative raw traces of potassium-evoked glutamate release in the DG. The black 
arrows mark where $\mathrm{KCl}$ was locally applied to the DG. The hash marks (//) indicate where $\sim 100$ seconds were removed to preserve space. 
A.
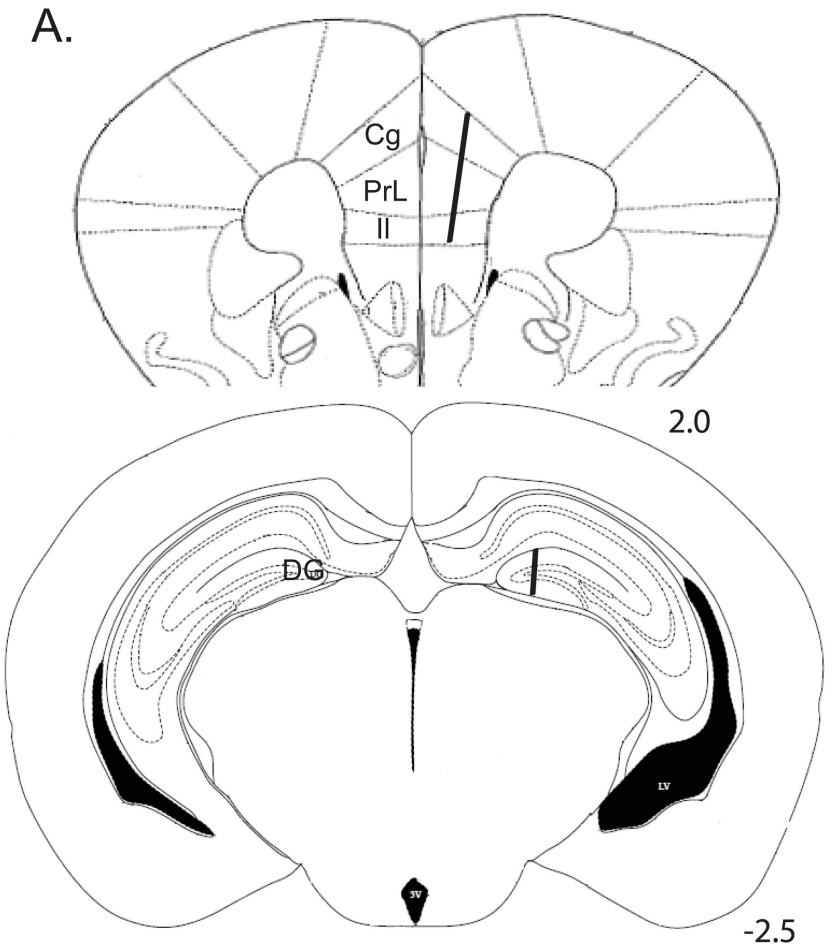

B.

\section{Glutamate Signal Parameters}

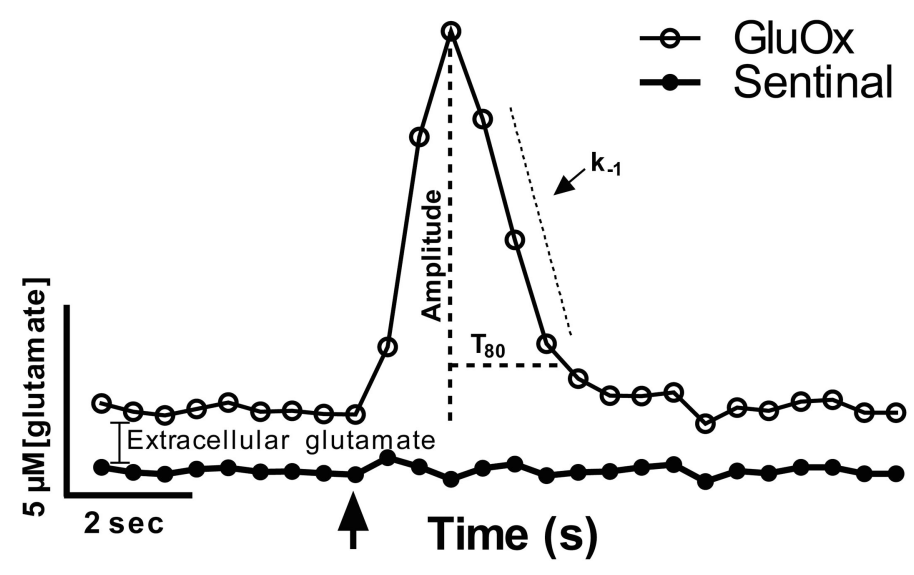

Figure 5.

DOX treatment impaired performance of MWM. (A) Distance traveled was similar between both groups. (B) Swim speed was significantly slower after DOX treatment. (C) The time it took to travel to the platform was significantly greater for DOX treated mice. Significance of the overall effect of DOX treatment using a repeated measures 2-way ANOVA is indicated with a black diamond $(p<0.05)$. Significant differences indicated with the post-hoc multiple comparison are indicated with a star $\left({ }^{*} \mathrm{p}<0.05\right.$ in comparison to control on the same day). Error bars represent the mean \pm SEM. 